\title{
Genotype by environment interaction for thousand-grain weight in spring barley using additive main effects and multiplicative interaction model
}

\author{
Zastosowanie modelu AMMI do analizy interakcji \\ genotypowo-środowiskowej masy tysiąca ziaren jęczmienia jarego
}

\author{
Anna Tratwal ${ }^{1 *}$, Kamila Nowosad $^{2}$, Jan Bocianowski ${ }^{3}$
}

\section{Summary}

The objective of this study was to assess genotype by environment interaction of thousand-grain weight in spring barley grown in South-West Poland by using the AMMI model. The study comprised of 25 spring barley genotypes (five cultivars: Basza, Blask, Antek, Skarb and Rubinek as well as all possible 10 two-way mixtures and 10 three-way mixtures combinations), evaluated at eight locations (two locations in four years) in a randomized complete block design, with four replicates. Thousand-grain weight of the tested genotypes ranged from $39.55 \mathrm{~g}$ (for Antek/Rubinek in Bąków 2011) to $53.25 \mathrm{~g}$ (for Skarb in Bąków 2010), with an average of $45.60 \mathrm{~g}$. In the AMMI analyses, $26.03 \%$ of the thousand-grain weight variation was explained by environment, $7.24 \%$ by differences between genotypes, and $14.48 \%$ by genotype by environment interaction. The cultivar Rubinek and mixtures Antek/Blask/Skarb and Antek/Rubinek/Skarb are recommended for further inclusion in the breeding program due to their high average thousand-grain weight and their high stability.

Key words: thousand-grain weight; AMMI; spring barley; stability

\section{Streszczenie}

Celem badań było zastosowanie modelu AMMI do estymacji interakcji genotypowo-środowiskowej masy tysiąca ziaren jęczmienia jarego rosnącego w południowo-zachodniej Polsce. Model AMMI zakłada addytywność efektów głównych genotypów i środowisk oraz efektów interakcji genotypowo-środowiskowej. Badanie obejmowało 25 genotypów jęczmienia jarego (pięć odmian: Basza, Blask, Antek, Skarb i Rubinek oraz wszystkie 10 możliwych mieszanek podwójnych i 10 mieszanek potrójnych), analizowanych w ośmiu środowiskach (dwie miejscowości w czterech latach) w doświadczeniach polowych, w układzie bloków losowanych kompletnych, w czterech powtórzeniach. Masa tysiąca ziaren badanych genotypów wynosiła od 39,55 g (dla Antek/Rubinek w Bąkowie w 2011 r.) do 53,25 g (dla Skarb w Bąkowie w 2010 r.), ze średnią masą tysiąca ziaren wynoszącą 45,60 g. Uzyskane wyniki wskazują, że 26,03\% całkowitej zmienności wyjaśnić można zmiennością środowiskową, 7,24\% przez różnice między genotypami, a 14,48\% interakcją genotypowośrodowiskową. Uzyskane wyniki pozwalają rekomendować odmianę Rubinek oraz mieszanki Antek/Blask/Skarb i Antek/Rubinek/Skarb do wykorzystania w programach hodowlanych ze względu na dużą średnią masę tysiąca ziaren oraz dużą ich stabilność.

Słowa kluczowe: masa tysiąca ziaren; model AMMI; jęczmień jary; stabilność

\footnotetext{
Instytut Ochrony Roślin - Państwowy Instytut Badawczy

Władysława Węgorka 20, 60-318 Poznań

${ }^{2}$ Uniwersytet Przyrodniczy we Wrocławiu

pl. Grunwaldzki 24A, 50-363 Wrocław

3Uniwersytet Przyrodniczy w Poznaniu

Wojska Polskiego 28, 60-637 Poznań

*corresponding author: a.tratwal@iorpib.poznan.pl
} 


\section{Wstęp / Introduction}

Praktyczne stosowanie integrowanej ochrony roślin wiąże się z wykorzystaniem, na ile to możliwe, wszelkich alternatywnych dla ochrony chemicznej metod zwalczania agrofagów. Zasadą jest, aby stosować różne metody, najbardziej efektywne i najmniej szkodliwe dla środowiska naturalnego w danym okresie rozwoju rośliny uprawnej.

Uprawa roślin w zasiewach mieszanych przyczynia się do zwiększenia bioróżnorodności na polach uprawnych. Dzięki poprawionej bioróżnorodności w łanie siewu mieszanego, w większym stopniu niż to ma miejsce w siewach czystych, działają rozmaite mechanizmy ekologiczne, przyczyniające się do zwiększenia wysokości i stabilności plonowania upraw (Finckh i wsp. 2000; Michalski i wsp. 2004; Gacek 2010).

Celem niniejszej pracy była ocena interakcji genotypowo-środowiskowej (GE) masy tysiąca ziaren odmian i mieszanek jęczmienia jarego z zastosowaniem modelu AMMI.

\section{Materiały i metody / Materials and methods}

Ścisłe doświadczenia polowe założone zostały w dwóch miejscowościach, tj. Hodowla Roślin Smolice Oddział Bąków Sp. z o.o. - Grupa IHAR, województwo opolskie $\left(50^{\circ} 42^{\prime} \mathrm{N}, 18^{\circ} 28^{\prime} \mathrm{E}\right)$ i Zakład Doświadczalny Oceny Odmian Kościelna Wieś, województwo wielkopolskie $\left(51^{\circ} 47^{\prime} \mathrm{N}\right.$, $\left.18^{\circ} 00^{\prime} \mathrm{E}\right)$, w ciągu czterech sezonów wegetacyjnych (2010, 2011, 2012 i 2013). Doświadczenia zostały założone w czterech powtórzeniach, w układzie split-plot na poletkach o powierzchniach: $10 \mathrm{~m}^{2}$ (Bąków) i 16,5 $\mathrm{m}^{2}$ (Kościelna Wieś). Do badań użyto pięć odmian jęczmienia jarego Basza (Ba), Blask (Bl), Antek (A), Skarb (S) i Rubinek (R) oraz ich 10 mieszanek dwuskładnikowych i 10 kombinacji trójskładnikowych. Udział komponentów mieszanek wynosił $1: 1(\mathrm{Ba} / \mathrm{Bl}, \mathrm{A} / \mathrm{Ba}, \mathrm{Ba} / \mathrm{S}, \mathrm{Ba} / \mathrm{R}, \mathrm{Bl} / \mathrm{A}, \mathrm{Bl} / \mathrm{S}, \mathrm{Bl} / \mathrm{R}$, $\mathrm{A} / \mathrm{S}, \mathrm{A} / \mathrm{R}, \mathrm{S} / \mathrm{R})$ lub $1: 1: 1(\mathrm{~A} / \mathrm{Ba} / \mathrm{Bl}, \mathrm{Ba} / \mathrm{Bl} / \mathrm{S}, \mathrm{Ba} / \mathrm{Bl} / \mathrm{R}$, $\mathrm{Ba} / \mathrm{S} / \mathrm{R}, \mathrm{A} / \mathrm{Bl} / \mathrm{S}, \mathrm{Bl} / \mathrm{A} / \mathrm{R}, \mathrm{A} / \mathrm{R} / \mathrm{S}, \mathrm{Bl} / \mathrm{R} / \mathrm{S}, \mathrm{A} / \mathrm{Ba} / \mathrm{S}, \mathrm{A} / \mathrm{Ba} / \mathrm{R})$.

Badane genotypy oraz ich mieszanki obserwowano pod kątem ciężaru masy tysiąca ziaren - jednego z ważniejszych elementów struktury polu. Przed zbiorem z każdego obiektu pobierano ręcznie po 100 kłosów, które następnie poddano omłóceniu. Uzyskane ziarno przeliczono na masę tysiąca ziaren.

Dwuczynnikowa analiza wariancji (ANOVA) została przeprowadzona do weryfikacji hipotezy o braku efektów genotypów (odmian i ich mieszanek), środowisk i interakcji genotypowo-środowiskowej masy tysiąca ziaren. Wartości średnie wyestymowane metodą najmniejszych kwadratów zostały równocześnie zastosowane $\mathrm{w}$ modelu AMMI (Additive Main effects and Multiplicative Interaction model) - model dwuczynnikowy, opisujący sumę efektów addytywnych (głównych) odmian i środowisk oraz efekty interakcji GE w multiplikatywnej postaci, GE - klasyfikacja lub interakcja genotypy $\times$ środowiska).
Model w pierwszej kolejności dopasowuje efekty addytywne dla genotypów (G) i środowisk (E), a następnie poprzez analizę składowych głównych (PCA) efekty multiplikatywne dla interakcji genotypowo-środowiskowej (GE). Model AMMI można zapisać jako (Gauch i Zobel 1990; Nowosad i wsp. 2017):

$$
y_{g e}=\mu+\alpha_{g}+\beta_{e}+\sum_{n=1}^{N} \lambda_{n} \gamma_{g n} \delta_{e n}+Q_{g e}
$$

gdzie $y_{g e}$ jest wartością średnią masy tysiąca ziaren dla genotypu $g$ w środowisku $e, \mu$ jest średnią ogólną, $\alpha_{g}$ jest efektem genotypowym, $\beta_{e}$ jest efektem środowiskowym, $N$ jest liczbą składowych głównych w dopasowanym modelu, $\lambda_{n}$ jest pierwiastkiem kwadratowym $n$-tej wartości własnej, $\gamma_{g n}$ jest $n$-tą składową główną dla genotypu, $\delta_{e n}$ jest $n$-tym wektorem własnym, $Q_{g e}$ jest błędem. Do porównania stabilności genotypów zastosowano tzw. wartość stabilności modelu AMMI (ASV) (Purchase i wsp. 2000):

$$
A S V=\sqrt{\left.\frac{S S_{I P C A 1}}{S S_{I P C A 2}}\left(I P C A_{1}\right)\right]^{2}+\left(I P C A_{2}\right)^{2}}
$$

gdzie SS oznaczają sumy kwadratów dla pierwszej (IPCA1) i drugiej (IPCA2) składowej głównej dla interakcji, IPCA i IPCA 2 są wartościami składowych głównych dla genotypów z modelu AMMI. ASV jest odległością od zera na dwuwymiarowym wykresie dwóch pierwszych składowych głównych. Niskie wartości ASV oznaczają większą stabilność genotypu poprzez środowiska. Poziom istotności w analizie PCA testowano testem $F$. Wszystkie analizy przeprowadzono z wykorzystaniem pakietu statystycznego GenStat 18.2.

\section{Wyniki i dyskusja / Results and discussion}

Trzy źródła zmienności były istotne statystycznie: 26,03\% całkowitej zmienności MTZ wyjaśnić można zmiennością środowiskową, 7,24\% przez różnice między genotypami, a 14,48\% interakcją genotypowo-środowiskową (tab. 1). Dwie pierwsze składowe główne dla interakcji genotypowo-środowiskowej wyjaśniały łącznie 76,75\% całego efektu masy tysiąca ziaren i były istotne statystycznie. Pierwsza składowa główna (IPCA 1) wyjaśniała 49,73\% zmienności wywołanej przez interakcję, a IPCA 2 wyjaśniała 27,03\%. Średnia MTZ badanych genotypów wynosiła od 39,55 g (dla Antek/Rubinek w Bąkowie w 2011 r.) do 53,25 g (dla Skarb w Bąkowie w 2010 r.), z wartością średnią MTZ równą 45,60 g (tab. 2). Średnia MTZ w środowiskach wynosiła od 43,35 g w Kościelnej Wsi w 2012 roku do 48,06 g w Kościelnej Wsi w latach 2010 i 2011 (tab. 2).

$\mathrm{Na}$ istotny wpływ interakcji genotypowo-środowiskowej na masę tysiąca ziaren jęczmienia jarego wskazują również 
Tabela 1. Analiza wariancji dla efektów głównych i interakcyjnych masy tysiąca ziaren jęczmienia jarego

Table 1. Analysis of variance of main effects and interactions for spring barley thousand-grain weight

\begin{tabular}{l|c|c|c|c|c}
\hline $\begin{array}{l}\text { Źródło zmienności } \\
\text { Source of variation }\end{array}$ & $\begin{array}{c}\text { Liczba stopni } \\
\text { swobody } \\
\text { Number of degrees } \\
\text { of freedom }\end{array}$ & $\begin{array}{c}\text { Suma kwadratów } \\
\text { Sum of squares }\end{array}$ & $\begin{array}{c}\text { Średni kwadrat } \\
\text { Mean squares }\end{array}$ & $\begin{array}{c}\text { Statystyka } F \\
F \text {-Statistic }\end{array}$ & $\begin{array}{c}\text { Procent wyjaśnianej } \\
\text { zmienności } \\
\text { Variability explained } \\
{[\%]}\end{array}$ \\
\hline $\begin{array}{l}\text { Genotypy (G) } \\
\text { Genotypes }\end{array}$ & 24 & 820 & 34,18 & $3,56^{* * *}$ & 7,24 \\
\hline $\begin{array}{l}\text { Środowiska (E) } \\
\text { Environment }\end{array}$ & 7 & 2947 & 421,07 & $26,11^{* * *}$ & 26,03 \\
\hline $\begin{array}{l}\text { GE Interakcja } \\
\text { Interactions }\end{array}$ & 168 & 1639 & 9,76 & $1,02^{*}$ & 14,48 \\
\hline IPCA 1 & 30 & 815 & 27,17 & $2,83^{* * *}$ & 49,73 \\
\hline IPCA 2 & 58 & 443 & 15,83 & $1,65^{*}$ & 27,03 \\
\hline Reszta - Residuals & 576 & 5528 & 9,93 & 1 & - \\
\hline Błąd - Error & $-58,6$ & - & - \\
\hline
\end{tabular}

***P $<0,001-\mathrm{P}<0.001$, IPCA - składowa główna dla interakcji - principal component of interaction

Tabela 2. Wartości średnie masy tysiąca ziaren dla genotypów i środowisk, wartości dwóch pierwszych składowych głównych testowanych odmian i mieszanek jęczmienia jarego oraz wartości stabilizacji modelu AMMI (ASV)

Table 2. Average values of thousand-grain weight, for genotypes and environments, principal component analysis values of tested spring barley cultivars and mixtures as well as AMMI stability value (ASV)

\begin{tabular}{|c|c|c|c|c|c|c|c|c|c|c|c|c|c|}
\hline \multirow{2}{*}{$\begin{array}{l}\text { Odmiany/Mieszanki } \\
\text { Cultivars/Mixtures }\end{array}$} & \multirow{2}{*}{$\begin{array}{l}\text { Kod } \\
\text { Code }\end{array}$} & \multicolumn{4}{|c|}{ Bąków } & \multicolumn{4}{|c|}{ Kościelna Wieś } & \multirow{2}{*}{$\begin{array}{l}\text { Średnia } \\
\text { Mean }\end{array}$} & \multirow{2}{*}{ IPCAg1 } & \multirow{2}{*}{ IPCAg2 } & \multirow{2}{*}{ ASV } \\
\hline & & 2010 & 2011 & 2012 & 2013 & 2010 & 2011 & 2012 & 2013 & & & & \\
\hline Basza & $\mathrm{Ba}$ & 45,54 & 41,42 & 41,28 & 42,35 & 46,18 & 46,18 & 39,89 & 45,73 & 43,57 & $-0,495$ & 0,053 & 0,91 \\
\hline Blask & $\mathrm{B} 1$ & 44,25 & 41,55 & 41,84 & 41,55 & 49,40 & 49,40 & 41,77 & 47,23 & 44,62 & $-1,544$ & 0,186 & 2,85 \\
\hline Antek & A & 46,88 & 43,38 & 45,82 & 44,17 & 49,25 & 49,25 & 41,88 & 42,80 & 45,43 & $-0,332$ & $-0,155$ & 0,63 \\
\hline Skarb & $\mathrm{S}$ & 53,25 & 46,93 & 49,01 & 48,88 & 47,10 & 47,10 & 46,58 & 45,88 & 48,09 & 1,680 & $-0,152$ & 3,09 \\
\hline Rubinek & $\mathrm{R}$ & 48,38 & 45,38 & 46,19 & 46,92 & 48,73 & 48,73 & 46,40 & 44,50 & 46,90 & 0,430 & $-0,013$ & 0,79 \\
\hline Basza/Blask & $\mathrm{Ba} / \mathrm{Bl}$ & 45,09 & 41,93 & 42,38 & 41,83 & 44,50 & 44,50 & 41,88 & 43,90 & 43,25 & 0,188 & $-0,252$ & 0,43 \\
\hline Antek/Basza & $\mathrm{A} / \mathrm{Ba}$ & 46,68 & 42,00 & 41,25 & 40,95 & 51,35 & 51,35 & 42,02 & 46,65 & 45,28 & $-1,845$ & 0,408 & 3,42 \\
\hline Basza/Skarb & $\mathrm{Ba} / \mathrm{S}$ & 50,11 & 43,90 & 43,88 & 46,32 & 47,02 & 47,02 & 42,45 & 44,48 & 45,65 & 0,604 & 0,213 & 1,13 \\
\hline Basza/Rubinek & $\mathrm{Ba} / \mathrm{R}$ & 46,90 & 44,02 & 45,98 & 43,20 & 47,25 & 47,25 & 42,85 & 43,10 & 45,07 & 0,168 & $-0,514$ & 0,60 \\
\hline Antek/Blask & $\mathrm{A} / \mathrm{Bl}$ & 45,92 & 44,77 & 44,24 & 43,97 & 50,85 & 50,85 & 41,83 & 44,52 & 45,87 & $-1,082$ & $-0,353$ & 2,02 \\
\hline Antek/Skarb & $\mathrm{A} / \mathrm{S}$ & 50,70 & 44,55 & 44,61 & 45,95 & 47,83 & 47,83 & & 45,52 & 46,47 & 0,524 & & 0,99 \\
\hline Antek/Rubinek & $\mathrm{A} / \mathrm{R}$ & 48,05 & 39,55 & 44,16 & 46,45 & 48,45 & 48,45 & 44,42 & 43,88 & 45,43 & 0,091 & 1,392 & 1,40 \\
\hline Blask/Skarb & $\mathrm{B} 1 / \mathrm{S}$ & 49,54 & 40,88 & 42,64 & 45,80 & 47,75 & 47,75 & 44,02 & 43,12 & 45,19 & 0,340 & 1,136 & 1,30 \\
\hline Blask/Rubinek & $\mathrm{Bl} / \mathrm{R}$ & 46,69 & 43,50 & 44,92 & 44,60 & 48,95 & 48,95 & 43,52 & 44,30 & 45,68 & $-0,306$ & 0,013 & 0,56 \\
\hline Rubinek/Skarb & $\mathrm{R} / \mathrm{S}$ & 51,70 & 47,65 & 46,11 & 45,82 & 47,28 & 47,28 & 46,05 & 44,58 & 47,06 & 1,077 & $-0,573$ & 2,06 \\
\hline Antek/Basza/Blask & $\mathrm{A} / \mathrm{Ba} / \mathrm{Bl}$ & 45,72 & 47,62 & 44,03 & 42,35 & 46,45 & 46,45 & 41,50 & 44,10 & 44,78 & $-0,012$ & $-1,605$ & 1,61 \\
\hline Antek/Blask/Skarb & $\mathrm{A} / \mathrm{Bl} / \mathrm{S}$ & 48,27 & 43,90 & 45,35 & 45,83 & 47,38 & 47,38 & 44,80 & 45,35 & 46,03 & 0,428 & 0,100 & 0,79 \\
\hline Antek/Basza/Rubinek & $\mathrm{A} / \mathrm{Ba} / \mathrm{R}$ & 47,22 & 44,15 & 43,40 & 43,67 & 49,65 & 49,65 & 43,26 & 43,75 & 45,59 & $-0,583$ & $-0,055$ & 1,07 \\
\hline Antek/Blask/Rubinek & $\mathrm{A} / \mathrm{Bl} / \mathrm{R}$ & 47,16 & 44,23 & 44,73 & 44,90 & 45,48 & 45,48 & 42,20 & 42,77 & 44,62 & 0,754 & $-0,459$ & 1,46 \\
\hline Antek/Basza/Skarb & $\mathrm{A} / \mathrm{Ba} / \mathrm{S}$ & 48,23 & 43,38 & 43,21 & 42,60 & 47,68 & 47,68 & 43,84 & 43,77 & 45,05 & $-0,056$ & 0,016 & 0,10 \\
\hline Blask/Rubinek/Skarb & $\mathrm{Bl} / \mathrm{R} / \mathrm{S}$ & 48,93 & 42,25 & 43,84 & 47,30 & 46,95 & 46,95 & 44,08 & 44,55 & 45,61 & 0,642 & 0,750 & 1,40 \\
\hline Basza/Blask/Rubinek & $\mathrm{Ba} / \mathrm{Bl} / \mathrm{R}$ & 47,09 & 45,95 & 46,05 & 45,12 & 49,20 & 49,20 & 41,61 & 46,15 & 46,30 & $-0,399$ & $-0,714$ & 1,02 \\
\hline Antek/Rubinek/Skarb & $\mathrm{A} / \mathrm{R} / \mathrm{S}$ & 49,62 & 42,88 & 44,48 & 46,67 & 48,75 & 48,75 & 44,34 & 44,33 & 46,23 & 0,256 & 0,686 & 0,83 \\
\hline Basza/Blask/Skarb & $\mathrm{Ba} / \mathrm{Bl} / \mathrm{S}$ & 47,85 & 47,95 & 44,44 & 43,38 & 49,07 & 49,07 & 43,42 & 45,00 & 46,27 & $-0,324$ & $-1,108$ & 1,26 \\
\hline Basza/Rubinek/Skarb & $\mathrm{Ba} / \mathrm{R} / \mathrm{S}$ & 49,31 & 42,40 & 42,85 & 45,00 & 48,95 & 48,95 & 44,45 & 45,62 & 45,94 & $-0,204$ & 0,773 & 0,86 \\
\hline Średnia - Mean & & 47,96 & 43,84 & 44,27 & 44,62 & 48,06 & 48,06 & 43,35 & 44,62 & 45,60 & - & - & - \\
\hline IPCAe1 & & 1,47 & 0,35 & 0,90 & 1,42 & $-1,92$ & $-1,92$ & 0,80 & $-1,10$ & - & - & - & - \\
\hline IPCAe2 & & 0,82 & $-2,68$ & $-0,82$ & 1,06 & 0,40 & 0,40 & 0,73 & 0,08 & - & - & - & - \\
\hline
\end{tabular}




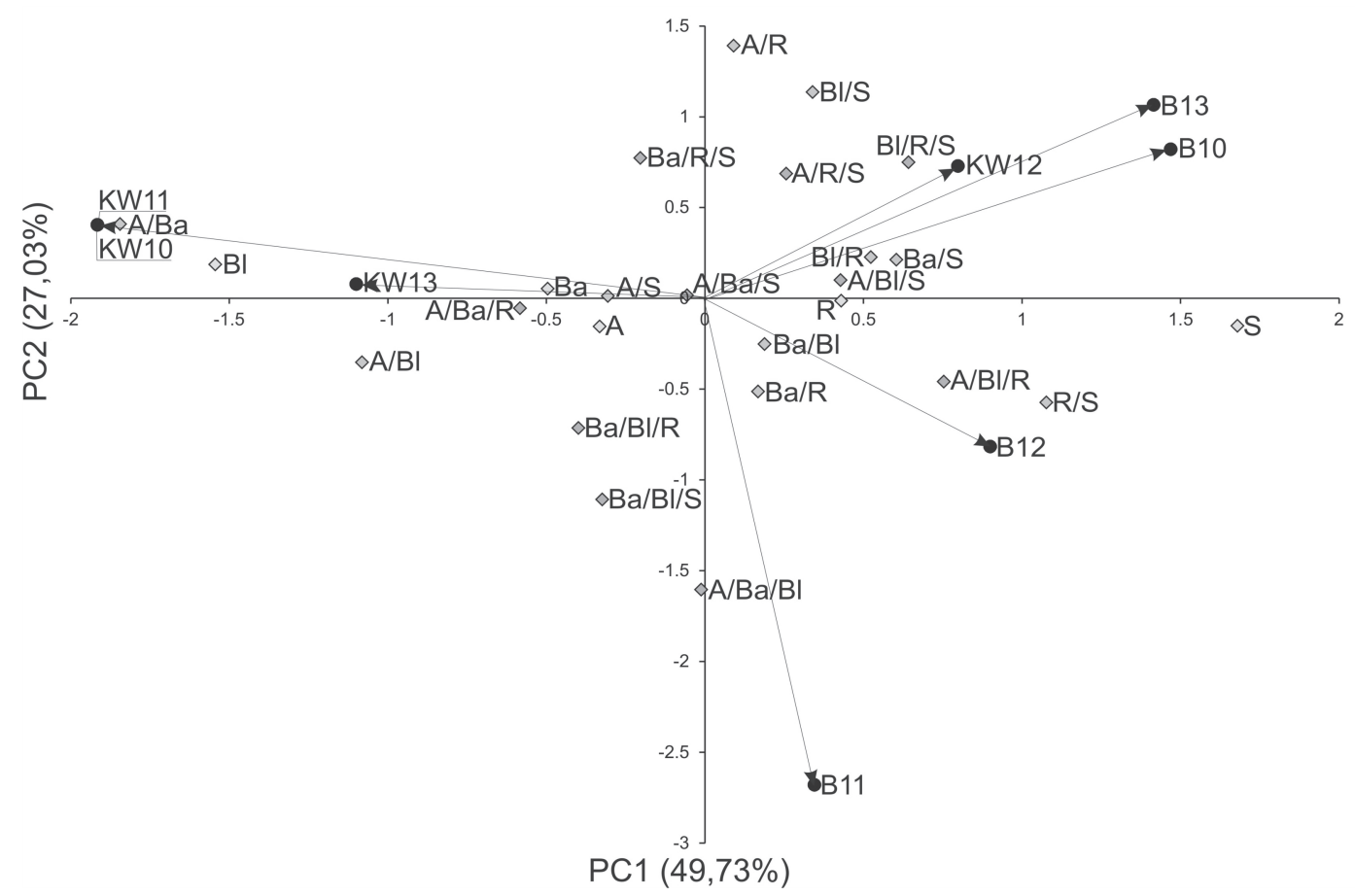

Rys. 1. Biplot dla interakcji genotypowo-środowiskowej masy tysiąca ziaren odmian i mieszanek jęczmienia jarego w ośmiu środowiskach, przedstawiający efekty pierwszej i drugiej składowej głównej (IPCA 1 i IPCA 2, odpowiednio)

Fig. 1. Biplot for genotype by environment interaction of thousand-grain weight in spring barley cultivars and their mixtures in eight environments, showing the effects of primary and secondary components (IPCA 1 and IPCA 2, respectively)

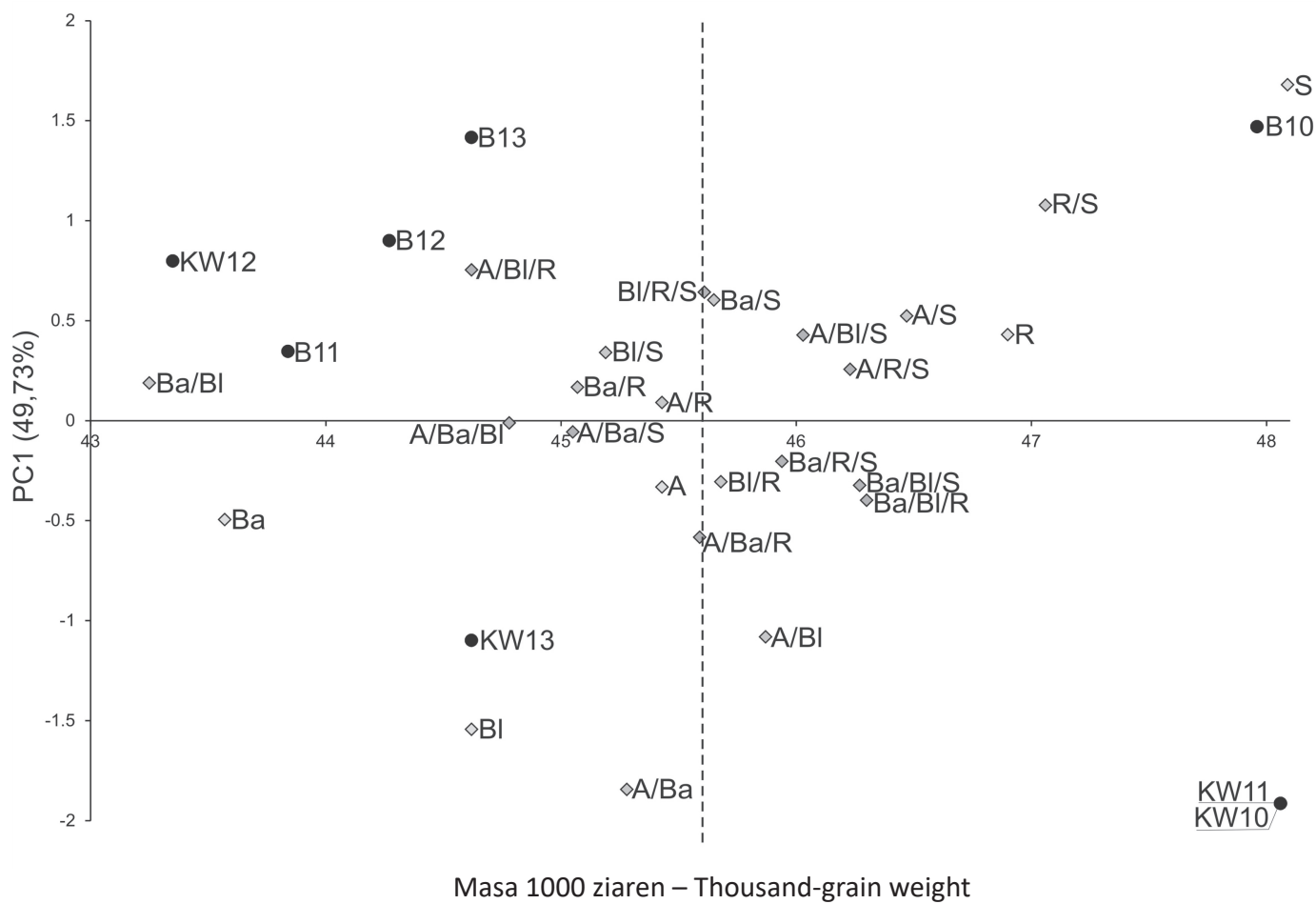

Rys. 2. Biplot dla pierwszej składowej głównej dla interakcji (IPCA 1) i średniej masy tysiąca ziaren. Linia pionowa w środku biplota oznacza średnią ogólną

Fig. 2. Biplot for the primary component of interaction (IPCA 1) and average mass of thousand-grain weight. Vertical line at the centre of biplot is the general mean 
wyniki badań innych autorów (Gołębiewski i wsp. 2012; Elakhdar i wsp. 2017; Laidig i wsp. 2017; Ziemińska i Tkaczuk 2017).

Wykres typu biplot dla analizy AMMI (rys. 1) przedstawia stabilność genotypów i środowisk oraz specyfikę interakcji genotypowo-środowiskowej. Dla badanych genotypów, wartości pierwszej składowej głównej dla interakcji wynosiły od -1,845 (Antek/Basza) do 1,680 (Skarb), natomiast dla badanych środowisk od -1,92 (Kościelna Wieś 2010 r. i 2011 r.) do 1,47 (Bąków 2010 r.) (rys. 1). Stabilność genotypu rozważana jest jako stała reakcja na zmienność warunków środowiskowych, stres biotyczny i abiotyczny, czynniki agronomiczne czy warunki pogodowe. Odmiana Blask i mieszanka Antek/Basza oddziaływały pozytywnie ze środowiskiem w Kościelnej Wsi w 2013 roku, a negatywnie w Bąkowie w 2010 roku (rys. 1, 2), natomiast odmiana Skarb wykazywała odwrotne odziaływanie z tymi środowiskami niż odmiana Blask. Mieszanka Antek/Basza/Blask oddziaływała pozytywnie w Bąkowie w 2011 roku, a negatywnie w Kościelnej Wsi w latach 2010 i 2011. Niektóre genotypy mają wysoką adaptację, jednakże większość z nich ma specyficzną adaptację środowiskową. Wartości stabilizacji AMMI (ASV) ukazują zmienność stabilności masy tysiąca ziaren 25 genotypów (tab. 2). Według Purchase i wsp. (2000) genotyp jest stabilniejszy im wartość ASV jest bliższa zeru. Konsekwentnie, mieszanki Antek/ /Basza/Skarb (z AVS równym 0,10), Basza/Blask $(0,43)$, Blask/Rubinek $(0,56)$ i Basza/Rubinek $(0,60)$ są najbardziej stabilne (tab. 2). Natomiast mieszanka Antek/Basza $(3,42)$ oraz odmiany Skarb $(3,09)$ i Blask $(2,85)$ były najmniej stabilne (tab. 2). Odmiana Rubinek oraz mieszanki Antek/ /Blask/Skarb i Antek/Rubinek/Skarb, ze stosunkowo dużą średnią masą tysiąca ziaren (odpowiednio - 46,90 g, 46,03 g i 46,23 g) i dobrą stabilnością (ASV równe, odpowiednio - 0,79, 0,79 i 0,83) są rekomendowane do włączenia do dalszych prac w programach hodowlanych (tab. 2, rys. 2).

\section{Wnioski / Conclusions}

1. Biplot AMMI pozwala na wizualizację efektów głównych genotypów w różnych środowiskach, a także bardzo ważnej interakcji genotypowo-środowiskowej.

2. Model AMMI dostarcza przydatnego narzędzia w diagnozowaniu interakcji GE i poprawie precyzji estymacji. Umożliwia grupowanie genotypów na podstawie podobieństwa obserwowanej cechy i identyfikacji potencjalnych trendów poprzez środowiska.

3. Wyniki analizy AMMI wykazały znaczącą interakcję genotypowo-środowiskową dla masy tysiąca ziaren.

4. Odmianę Rubinek oraz mieszanki Antek/Blask/Skarb i Antek/Rubinek/Skarb rekomenduje się do wykorzystania w programach hodowlanych jęczmienia jarego ze względu na dużą średnią masę tysiąca ziaren oraz ich dużą stabilność.

\section{Literatura / References}

Elakhdar A., Kumamaru T., Smith K.P., Brueggeman R.S., Capo-chichi L.J.A., Solanki S. 2017. Genotype by environment interactions (GEIs) for barley grain yield under salt stress condition. Journal of Crop Science and Biotechnology 20 (3): 193-204. DOI: 10.1007/ s12892-017-0016-0.

Finckh M.R., Gacek E.S., Goyeau H., Lannou Ch., Merz U., Mundt C.C., Munk L., Nadziak J., Newton A.C., de Vallavieille-Poppe C., Wolfe M.S. 2000. Cereal variety and species mixtures in practice, with emphasis on disease resistance. Agronomie 20 (7): $813-837$. DOI: 10.1051 /agro:2000177.

Gacek E. 2010. Sugestie wynikające z wieloletnich badań mieszanek odmianowych jęczmienia i pszenicy. Materiały Konferencji Naukowej „Znaczenie gospodarcze i biologia plonowania upraw mieszanych”. Poznań/Zielonka, 3-5 marca 2010: 1-9.

Gauch H.G., Zobel R.W. 1990. Imputing missing yield trial data. Theoretical and Applied Genetics 79 (6): 753-761. DOI: 10.1007/ BF00224240.

Gołębiewski D., Myszka K., Burek J., Mańkowski D.R., Boros D. 2012. Badania zmienności genetycznej i wpływu środowiska na cechy determinujące wartość browarną ziarna rodów jęczmienia jarego włączonych do badań przedrejestrowych w 2011 roku. [Study of genetic variation and environmental impact on traits that determine malting quality of spring barley lines included in preliminary trials in 2011]. Biuletyn Instytutu Hodowli i Aklimatyzacji Roślin 263: 19-31.

Laidig F., Piepho H.-P., Rentel D., Drobek T., Meyer U. 2017. Breeding progress, genotypic and environmental variation and correlation of quality traits in malting barley in German official variety trials between 1983 and 2015. Theoretical and Applied Genetics 130 (11): 2411-2429. DOI: 10.1007/s00122-017-2967-4.

Michalski T., Kowalik I., Idziak R., Horoszkiewicz-Janka J. 2004. Mieszanki jako ekologiczna metoda uprawy zbóż. Wybrane zagadnienia ekologiczne we współczesnym rolnictwie. Monografia. Przemysłowy Instytut Mechanizacji Rolnictwa, Poznań: 28-36.

Nowosad K., Liersch A., Poplawska W., Bocianowski J. 2017. Genotype by environment interaction for oil content in winter oilseed rape (Brassica napus L.) using additive main effects and multiplicative interaction model. Indian Journal of Genetics and Plant Breeding 77 (2): 293-297. DOI: 10.5958/0975-6906.2017.00039.6.

Purchase J.L., Hatting H., van Deventer C.S. 2000. Genotype $\times$ environment interaction of winter wheat (Triticum aestivum L.) in South Africa: II. Stability analysis of yield performance. South African Journal of Plant and Soil 17 (3): 101-107. DOI: $10.1080 / 02571862.2000 .10634878$.

Ziemińska J., Tkaczuk C. 2017. Wpływ terminu siewu i odmiany na plonowanie jęczmienia jarego w warunkach środkowo-wschodniej Polski. [Effect of sowing date and variety on yielding of spring barley in central-eastern Poland]. Fragmenta Agronomica 34 (1): 126-134. 